\title{
INOVASI INDO-MUDSKIPPER-BOOK BERBASIS UNITY OF SCIENCES SEBAGAI SUMBER BELAJAR MAHASISWA PENDIDIKAN BIOLOGI
}

\author{
Saifullah Hidayat ${ }^{1}$, Andi Raharjo ${ }^{2}$, Musthofa ${ }^{3}$ \\ ${ }^{1,2}$ Prodi Pendidikan Biologi, Fakultas Sains dan Teknologi, UIN Walisongo Semarang \\ ${ }^{3}$ Prodi Pendidikan Agama Islam, Fakultas Ilmu Tarbiyah dan Keguruan, UIN Walisongo \\ Semarang
}

\begin{abstract}
Abstrak
Penelitian ini didasarkan pada kebutuhan informasi tentang ikan gelodok bermuatan unity of science. Indo-mudskipper-book menjadi sarana alternatif untuk memenuhi kebutuhan informasi ikan gelodok pada perkuliahan zoology vertebrata. Tujuan penelitian ini adalah untuk mengembangkan buku ikan gelodok dan menguji kualitas buku yang telah dikembangkan. Metode yang digunakan untuk mengembangkan buku ikan gelodok adalah Research and Development (R\&D) dengan model 4D (Design, Define, Develop, Disseminate) yang dikembangkan oleh Thiagarajan tahun 1974. Instrumen pengumpulan data menggunakan wawancara, observasi, dan angket validasi oleh ahli materi, ahli media, ahli integrasi serta mahasiswa sebagai respon pengguna. Data yang diperoleh kemudian dianalisis secara deskriptif dan menggunakan skala likert. Hasil menunjukkan bahwa Indo mudskipper book memuat informasi terkait keragaman ikan gelodok di Indonesia dilengkapi dengan penjelasan integrasi sains islam. Uji kelayakan menunjukkan persentase hasil validasi dari ahli materi sebesar $95 \%$, ahli media sebesar $73 \%$, ahli integrasi sebesar $88 \%$. Uji skala kecil sebesar $89 \%$ dan Uji skala lebih luas sebesar $85 \%$. Hal tersebut menunjukkan bahwa buku ikan gelodok layak digunakan sebagai sumber belajar mandiri mahasiswa pendidikan biologi.
\end{abstract}

Kata kunci: Buku, Ikan Gelodok, Unity of Sciences

\section{PENDAHULUAN}

Pendidikan yang diberikan di perguruan tinggi, disajikan secara sistematis dengan mencakup berbagai program studi di dalamnya. Salah satunya adalah program studi pendidikan Biologi. Program studi Pendidikan Biologi di UIN Walisongo menyediakan beberapa mata kuliah yang wajib diambil mahasiswa diantaranya adalah Zoologi Vertebrata. Zoologi vertebrata adalah Mata kuliah yang mengkaji teori dan praktik tentang hewan vertebrata yang mencakup sistematika/taksonomi (kedudukan

Universitas Islam Negeri Walisongo

Email: hidayatsaifullah@walisongo.ac.id
(C)2020 Universitas Islam Negeri Walisongo

ISSN: 2088-7868, e-ISSN 2502-5708 
Vertebrata, klasifikasi, identifikasi dan tata nama) beserta kajian struktur morfologi, anatomi, histologi, fisiologi, ekologi, biogeografi dan peranan dari hewan vertebrata bagi kehidupan manusia (Naskah Akademik Pendidikan Biologi, 2016).

Berdasarkan observasi yang dilakukan pada perkuliahan Zoologi vertebrata kelas Pendidikan Biologi angkatan 2017 pada semester genap 2018/2019 diperoleh informasi bahwa sumber belajar yang umumnya digunakan adalah buku biologi umum (Campbell) dan buku-buku zoology secara umum yang belum mengintegrasikan paradigma kesatuan ilmu terutama integrasi nilai-nilai islam pada materi Zoologi Vertebrata. Buku yang digunakan rujukan juga belum ada yang spesifik membahas tentang ikan gelodok pada kelas Pisces. Padahal ikan gelodok tersebar di pesisir pantai jawa yang terdapat lumpur dan eksistem mangrove. Sebagian besar ikan amfibi (ikan gelodok) ditemukan di daerah tropis dan subtropis dengan sebaran geografis di seluruh Indo-pasifik dan lautan Pasifik Afrika. Mudskipper hidup pada temperatur udara dan air $21-30^{\circ} \mathrm{C}$ dan kelembaban $60-80 \%$. Spesies ikan amfibi yang ditemukan di daerah tropis lebih amfibious dibanding di daerah lain (Al-Behbehani dan Ebrahim, 2010).

Ikan gelodok atau ikan bekatul adalah sebutan untuk spesies ikan anggota Famili Gobidae yang biasa digunakan oleh orang Indonesia. "Ikan gelodok termasuk kategori ikan amfibi yang didefinisikan oleh Gordon et al. (1969) sebagai ikan yang menghabiskan waktunya dengan keluar dari air atau berada di daratan sebagian dari siklus hidupnya”. Sayer dan Deveport (1991) juga menyebutkan bahwa ikan amfibi secara umum aktif keluar dari air atau melompat menuju daratan.

Kebutuhan informasi yang tinggi bagi mahasiswa menjadi salah satu komponen pendidikan yang harus dipenuhi. Sumber belajar berupa buku dapat dijadikan salah satu solusi untuk memenuhi kebutuhan informasi mahasiswa. Pentingnya sumber belajar yang berkaitan dengan sarana dan prasarana telah diatur oleh pemerintah dalam BAB XII UU tentang Sistem Pendidikan Nasional (2003) dalam (Sitepu, 2014:33) bahwa setiap satuan pendidikan harus memiliki sarana dan prasarana yang menunjang proses belajar mengajar sesuai dengan perkemangan pendidikan. Sarana dan prasarana yang memadai akan meningkatkan potensi fisik, kecerdasa intelektual, kecerdasan emosional, dan perkembangan pelajar.

Integrasi menjadi salah satu prinsip dalam melakukan pengembangan paradigma ilmu pengetahuan (unity of science) (Fanani, 2015). Integrasi adalah mengumpulkan 
dua entitas yang berbeda di satu tempat, namun masing-masing ilmu agama diajarkan dengan metodologinya sedangkan ilmu umum diajarkan dengan metodologinya tidak berubah. Berbeda dengan ilmu agama Islam yang memiliki metode bersumber pada AlQur'an dan Al-Hadits. Metode pendidikan dalam sudut pandang Islam bertujuan untuk membentuk insan kamil sebagaimana yang dikemukakan oleh Abdurrahman AnNahlawi terdapat tujuh metode pendidikan Islam, yaitu metode hiwar, qishash, amstal, keteladanan, pembiasaan diri dan pengalaman, mauidhah /keteladanan, dan targih wa tarhib (Rosyadi, 2009). Penyisipkan integrasi nilai Islam adalah agar terbentuk karakter peserta didik yang beriman dan dapat meningkatkan ketaqwaan kepada Allah SWT melalui fenomena kekuasaan Allah SWT (Irawati, 2015).

Indo-Mudskipper-Book adalah buku yang akan membahas materi tentang keanekaragaman ikan gelodok (Mudskipper) di Indonesia beserta aspek biologinya meliputi struktur (anatomi, morfologi), fisiologi, taksnomi dan perananya bagi kehidupan manusia (Hidayat, 2020). Buku ini dikembangkan tidak hanya dalam perspektif sains (biologi) saja, tetapi dibahas pula integrasinya dalam perspektif islam. Sumber belajar "Indo-Mudskipper-Book" disusun berdasarkan analisis kebutuhan mahasiswa terhadap sumber belajar mata kuliah Zoologi vertebrata.

Pengembangan "Indo-Mudskipper-Book" diharapkan dapat memenuhi kebutuhan informasi mahasiswa. Penelitian pengembangan ini bertujuan untuk mengembangkan dan menguji kualitas buku ikan gelodok berintegrasi Islam sebagai sumber belajar mata kuliah zoology vertebrata.

\section{METODE PENELITIAN}

Penelitian ini menggunakan metode pengembangan (Research and Development) pada sumber belajar berupa pengembangan produk Buku Ikan gelodok. Buku ini bersifat sebagai sumber belajar untuk melengkapi dan memenuhi kebutuhan informasi mahasiswa pendidikan biologi. Model pengembangan yang dipilih oleh peneliti adalah 4-D (Define, Design, Develop, Disseminate) yang dikembangkan oleh Thiagarajan tahun 1974 (Mulyatiningsih, 2011). Tahapan yang dilakukan oleh peneliti adalah define, design, dan develop. Tahap disseminate dapat disempurnakan pada penelitian selanjutnya.

Tahap define (pendifinisian) dilakukan untuk membatasi syarat-syarat 
pengembangan melalui analisis kebutuhan. Langkah-langkah pada tahap pendefinisian meliputi: 1. Analisis ujug depan (front and analysis) dilakukan dengan mendiagnosis potensi ikan gelodok tidak hanya sebagai ikan liar saja melainkan dikembangkan sebagai sumber belajar pada materi pisces. 2. Analisis mahasiswa (learner analyze) dilaksanakan dengan teknik wawancara kepada mahasiswa pendidikan biologi tentang pengetahuan materi biologi, minat mahasiswa terhadap sumber belajar, kemampuan mahasiswa dalam memenuhi kebutuhan sehari-hari, dan sikap mahasiswa dalam menerapkan ilmu pada kehidupan sehari-hari. 3. Analisis tugas (taks analyze) berupa pengumpulan materi pisces dengan teknik wawancara dengan dosen ahli zoologi didukung dengan referensi berupa buku dan artikel jurnal penelitian. 4. Analisis konsep (concept analyze) meliputi dua tahapan. Pertama analisis Kompetensi Inti (KI) dan Kompetensi Dasar (KD) pada materi pisces yang sesuai dengan kurikulum KKNI dan KOBI. Kedua dilakukan dengan mengumpulkan informasi tentang materi pisces (ikan gelodok) berdasarkan sumber yang relevan. 5. Tujuan Instruksional khusus (specifying instructional objectives) berupa tujuan pembelajaran dari hasil analisis tugas dan analisis konsep untuk dasar penyusunan instrumen dan perancangan sumber belajar.

Tahap design (perancangan) merupakan tahap pengembangan sumber belajar yang dilakukan untuk mempersiapkan dan menyusun bahan materi buku. Proses perancangan juga dilakukan penyusunan lembar validasi dan angket. Tahapan yang dilakukan pada perancangan meliputi: 1. Perancangan pengembangan buku ikan gelodok. 2. Penyusunaan desain buku dimulai dari menyusun topik materi, sampling ikan gelodok, memilih software unttuk mendesain dan menyususn buku. 3. Pencetakan buku.

Tahap develop (pengembangan) bertujuan untuk menyempurnakan perangkat pembelajaran melalui validasi dan uji coba. Pengembangan buku terdiri dari dua tahap meliputi: 1. Penilaian ahli (expert apprasial) untuk mengetahui persentase kevalidan buku oleh ahli materi, ahli media, dan ahli integrasi. 2. Pengujian pengembangan (developmental testing) diterapkan kepada mahasiswa. Uji pengembangan terbagi menjadi uji coba skala terbatas dan uji coba skala lebih luas. Uji coba skala terbatas terdiri dari 10 mahasiswa. Uji coba skala lebih luas dengan 68 mahasiswa untuk mengetahui kelayakan buku.

Subjek penelitian adalah mahasiswa pendidikan biologi UIN Walisongo 
Semarang angkatan 2018 yang dipilih menggunakan teknik purposive sampling. Macam-macam teknik pengumpulan data yang dilakukan peneliti diantaranya teknik wawancara, teknik observasi, teknik dokumentasi, dan teknik angket. Wawancara dilakukan dengan mahasiswa dan dosen zoologi. Observasi dilaksanakan di perkuliahan dan laboratorium. Teknik dokumentasi dengan menyimpan berkas RPS dan dokumentasi foto ikan gelodok. Teknik angket untuk menguji validasi buku oleh ahli materi, ahli media, dan ahli integrasi, serta uji kelayakan kepada mahasiswa.

\section{Uji Validasi dan Uji Coba Skala Terbatas}

Uji validasi buku dilakukan oleh para validator ahli. Uji coba skala terbatas diterapkan kepada mahasiswa. Data yang diperoleh dari validator dan mahasiswa dianalisis menggunakan rumus statistik berikut ini:

Presentase $=\frac{A}{B} \times 100 \%$

\section{Keterangan :}

A = Banyaknya skor yang diperoleh

$\mathrm{B}=$ Skor maksimal

Tingkat validasi dari data validator terhadap penggunaan buku ikan gelodok disajikan dalam Tabel 1.

Tabel 1. Keterangan Persentase dan Tingkat Validasi

\begin{tabular}{cc}
\hline Persentase & Tingkat Validasi \\
\hline $0-20 \%$ & Sangat tidak valid, tidak boleh digunakan \\
$21-40 \%$ & Tidak valid, tidak boleh digunakan \\
$41-60 \%$ & Kurang valid, perlu revisi keseluruhan \\
$61-80 \%$ & Valid, perlu revisi skala kecil \\
$81-100 \%$ & Sangat valid, tanpa revisi \\
\hline
\end{tabular}

(Sumber: Akbar, 2013)

Persentase $41 \%$ menjadi batas minimum buku dapat digunakan sebagai sumber belajar dan memerlukan revisi. Revisi dilakukan untuk memperbaiki produk sehingga dapat dilanjutkan pada uji coba skala lebih luas.

\section{Uji Lapangan Skala Lebih Luas}

Uji lapangan skala lebih luas dilakukan untuk mengetahui kelayakan buku ikan gelodok kepada mahasiswa. Analisis data dari mahasiswa menggunakan rumus statistika persentase yakni: 
Presentase $=\frac{A}{B} \times 100 \%$

Keterangan :

$\mathrm{A}=$ Banyaknya skor yang diperoleh

$\mathrm{B}=$ Skor maksimal

Pengelompokan kategori kelayakan buku berdasarkan persentase yang didapat dilihat pada Tabel 2.

Tabel 2. Keterangan Persentase dan Tingkat Kelayakan

\begin{tabular}{cc}
\hline Persentase & Tingkat Kelayakan \\
\hline $0-20 \%$ & Tidak layak \\
$21-40 \%$ & Kurang layak \\
$41-60 \%$ & Cukup layak \\
$61-80 \%$ & Layak \\
$81-100 \%$ & Sangat layak \\
\hline & (Sumber: Akbar, 2013)
\end{tabular}

\section{HASIL DAN PEMBAHASAN}

Karakteristik pengembangan buku (Indo-Mudskipper-book) terdiri atas halaman sampul, halaman redaksi, kata pengantar, daftar isi, materi pengenalan ikan gelodok, jenis ikan gelodok di Indonesia, sudut pandang ikan gelodok dalam perspektif islam, glosarium, daftar pustaka dan biodata penulis. Model pengembangan Buku menggunakan 4D. Desain Buku menggunakan software corel draw X4 dan disusun menggunakan microsoft office 2007. Buku ikan gelodok berbentuk media cetak dengan sampul kertas CTS A5 dan isi menggunakan kertas HVS A5. Data diperoleh dari validasi para ahli, dan mahasiswa. Saran dan masukan dari validator digunakan sebagai dasar penyempurnaan produk agar sesuai dengan kebutuhan di masyarakat.

\section{Data Hasil Validasi Oleh Ahli}

Data validasi diperoleh dari para ahli, guru biologi, dan peer reviewer. Peranan penting ahli materi adalah memberikan koreksi terhadap kebenaran informasi pada buku. Aspek validasi ahli materi meliputi cakupan materi, keakuratan materi, kegiatan yang mendukung materi, materi mengembangkan kemampuan berfikir, penggunaan bahasa, penggunaan istilah atau simbol, dan evaluasi belajar. Ahli media berkaitan erat 
dengan tata letak dan ilustrasi pada buku. Aspek validasi media meliputi organisasi penyajian umum, kebermanfaatan penyajian, tampilan umum, dan kelengkapan buku. Ahli integrasi sebagai validator keterkaitan ilmu pada buku. Aspek validasi meliputi ayatisasi nilai Islam dan humanisasi ilmu keislaman.

Validator memberikan penilaian melalui instrumen berupa angket yang telah dikirim. Data persentase hasil validasi penilaian buku disajikan pada Grafik 1.

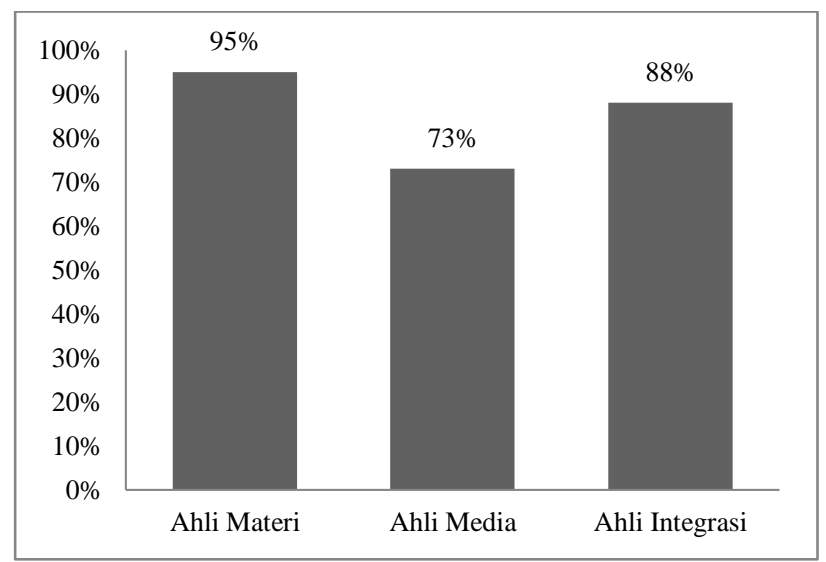

Grafik 1. Persentase Hasil Validasi

Persentase penilaian hasil validasi dari ahli materi, ahli media dan ahli integrasi menunjukkan bahwa buku sangat valid digunakan sebagai sumber belajar. Hasil persentase dari ahli media sebesar $73 \%$ yang menunjukkan bahwa buku valid digunakan sebagai sumber belajar namun diperlukan revisi skala kecil. Masukan dan saran dari para ahli digunakan untuk memperbaiki dan menyempurnakan buku sehingga dapat dilanjutkan pada uji lapangan.

\section{Data Uji Lapangan Skala Terbatas}

Buku yang telah diperbaiki pada uji validasi kemudian diujikan kepada 9 mahasiswa. Jumlah mahasiswa yang sedikit termasuk dalam langkah uji lapangan skala terbatas. Aspek validasi pada uji lapangan skala terbatas meliputi cakupan materi, penyajian, bahasa, dan kesesuaian sajian. Data persentase hasil validasi uji lapangan skala terbatas dapat disajikan pada grafik 2. 


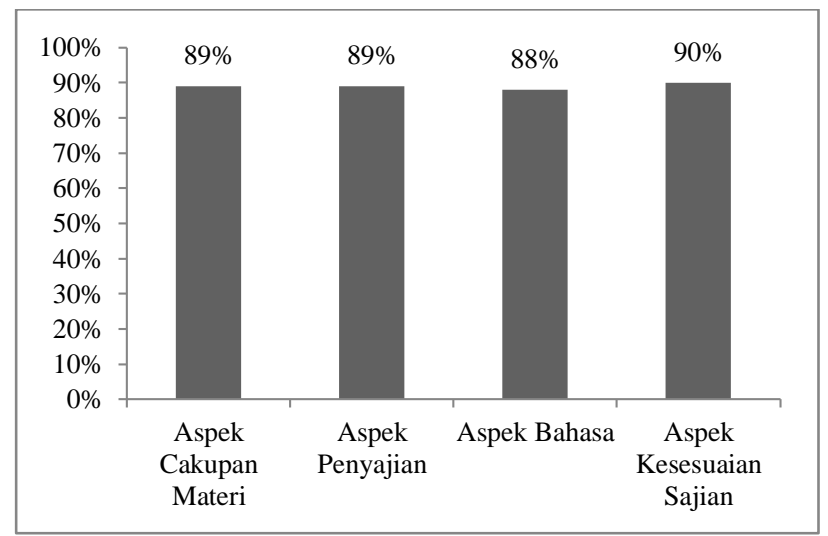

Grafik 2. Persentase Hasil Uji Lapangan Skala Terbatas

Data rata-rata persentase hasil uji lapangan skala terbatas sebesar 89\%. Analisis deskriptif dari persentase tersebut menunjukkan bahwa buku sangat valid digunakan sebagai sumber belajar tanpa revisi. Hasil tersebut memberikan dasar peneliti untuk menguji buku pada uji lapangan skala lebih luas.

\section{Data Uji Lapangan Skala Lebih Luas}

Uji lapangan skala lebih luas dilakukan untuk mengetahui kelayakan buku. Penilaian dilakukan oleh 68 mahasiswa pendidikan biologi melalui instrumen berupa angket. Aspek kelayakan meliputi cakupan materi, penyajian, bahasa, dan kesesuaian sajian. Data persentase hasil penilaian buku pada uji lapangan skala lebih luas disajikan pada grafik 3.

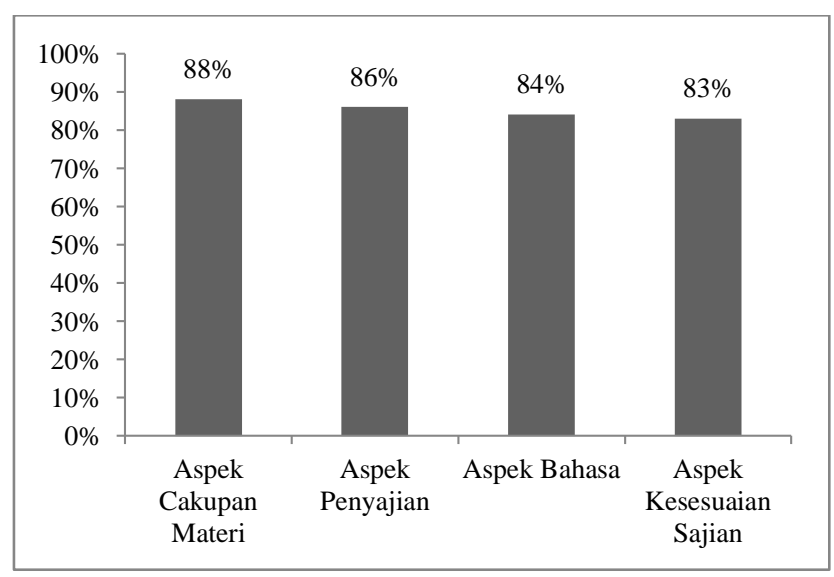

Grafik 3. Persentase Hasil Uji Lapangan Skala Lebih Luas

Data rata-rata hasil uji lapangan skala lebih luas sebesar $85 \%$. Nilai persentase kelayakan yang tergolong sangat layak dimulai dari 81\%-100\% (Sudrajat, 2015). Analisis deskriptif dari persentase tersebut menunjukkan bahwa buku ikan gelodok sangat layak digunakan sebagai sumber belajar sebagaimana penelitian yang dilakukan 
Yaqin dkk (2017) bahwa sumber belajar berbasis islam layak digunakan sebagai sumber belajar materi biologi.

\section{SIMPULAN}

Hasil dan pembahasan pada penelitian pengembangan buku ikan gelodok dapat disimpulkan bahwa pengembangan menghasilkan produk berupa sumber belajar buku ikan gelodok yang bermuatan unity of science (integrasi sains dan islam) dan persentase uji kelayakan buku ikan gelodok termasuk dalam kategori sangat layak sebagai sumber belajar. Data tersebut berdasarkan penilaian dari ahli media, ahli materi, ahli integrasi, dan mahasiswa dan memberikan respon yang baik.

\section{DAFTAR PUSTAKA}

Al-Behbehani, B.E and Ebrahim, H.M.A. 2010. Enviromental Studies on The Mudskipper in The Intertidal Zone of Kuwait Bay. Journal of Nature and sains 8 (5): 79-89.

Akbar, Sa'dun. 2013. Instrumen Perangkat Pembelajaran. Bandung : Remaja Rosdakarya Offset.

Gordon, M.S., Boetius, I., Evans, D.H., Carthy, R.Mc., and Oglesby, L.C. 1969. Aspects of The Physiology of Terestrial Life in Amphibious Fishes. I. The Mudskipper, Periophthalmus sobrinus. Journal of Experimental Biology. 50 : 141149.

Hidayat, S., 2020. Kajian Ikan Gelodok di Indonesia Bermuatan Unity of Science. Alinea Media Dipantara.

Irawati, I. 2015. Pengembangan Ensiklopedia Keanekaragaman Tumbuhan Angiospermae Berbasis Potensi Lokal di MTs Negeri Seyehan Dengan Muatan Keislaman. Skripsi. Yogyakarta: Universitas Islam Negeri Sunan Kalijaga.

Mulyatiningsih, E. 2011. Metode Penelitian Terapan Bidang Pendidikan. Yogyakarta : Alfabeta.

Muhyar Fanani. 2014. Transformasi Paradigma Dan Implikasinya Pada Desain Kurikulum Sains: Studi atas UIN Syarif Hidayatullah, UIN Sunan Kalijaga, dan UIN Maliki. Semarang : UIN Walisongo

Rosyadi, K. 2009. Pendidikan Profetik. Yogyakarta : Pustaka Belajar. 
Rudyatmi Ely, Endah Peniati, Ning Setiati. 2016. Hakekat Biologi Sebagai Ilmu. Kementrian Pendidikan dan Kebudayaan Direktorat Jendral Guru dan Tenaga Kenpendidikan.

Sayer, M.D.J and Davenport, J. 1991. Amphibious Fish: Why Do The Leave Water? Review in fish biology and Fisheries, 1 :159-181.

Sitepu. 2014. Pengembangan Sumber Belajar. Depok : Rajagrafindo Persada.

Sudrajat, A. 2015. Pengembangan Buku Ajar Kimia SMA/MA Terintegrasi Nilai-Nilai Karakter Siswa. Jurnal Penelitian Bidang Pendidikan. 21(1): 43-49.

Sugiyono. 2018. Metode Penelitian Pendidikan Pendekatan Kuantitatif, Kualitatif, dan $R \& D$. Bandung : Penerbit Alfabeta.

Sudjana dan A. Rifai. 2000. Sumber Belajar dan Alat Pelajaran. Jakarta : Bumi Aksara. 2002. Media Pembelajaran. Bandung : Sinar Baru Algensindo.

Tim penyusun. 2016. Naskah Akademik Pendidikan Biologi UIN Walisongo Semarang. Yaqin, M.A., Astuti, E.W., Anggraini, C.E.A., Hidayatullah, A.F. 2020. Integrasi AyatAyat Al-Qur'an dalam Pembelajaran Sains (Biologi) Berdasarkan Pemikiran Ian G. Barbour. Jurnal Kajian Pendidikan Sains. 6(1): 78-83 